\title{
Ethylene Dichloride Disruption of Fertility in Male Mice
}

\author{
Harold J. Daigle, Jr. ${ }^{1}$, Derek N. Cole ${ }^{1}$, J. Andrew Carlson ${ }^{2}$, William R. Lee ${ }^{1}$ and \\ Vincent L. Wilson ${ }^{1,3, *}$
}

${ }^{I}$ Department of Biological Sciences, Louisiana State University, Baton Rouge, LA 70803; ${ }^{2}$ Department of Pathology,
Albany Medical College, Albany, NY 12208 and ${ }^{3}$ Department of Environmental Sciences, Louisiana State University
and Veterinary Medical School, Baton Rouge, LA 70803, USA

\begin{abstract}
Ethylene dichloride (EDC) is a high use compound in chemical industry today. Although a potent alkylating agent and carcinogen, EDC has not been associated previously with adverse fertility consequences. Intraperitoneal 5 to 40 $\mathrm{mg} / \mathrm{kg}$ once a day for five days in C57BL/6 mice rendered males infertile for 6 months and longer. Two of three mice treated with EDC at $5 \mathrm{mg} / \mathrm{kg}$ recovered to fertility after a 3 and 5-week sterile period, respectively. Significant testicular pathology was evident within 8 days post treatment with EDC, which progressed to resemble Sertoli Cell-Only syndrome. Although the observed effects on Leydig cell populations were equivocal, a precipitous loss of spermatogonia was evident with increasing time post EDC treatment for mice dosed with either 5 or $10 \mathrm{mg} / \mathrm{kg}$ of EDC. These results suggest that intraperitoneal EDC adversely impacts the testes and spermatogenesis in mice.
\end{abstract}

Key Words: Ethylene dichloride, dihaloethane, testiscular toxicity, spermatogenesis.

\section{INTRODUCTION}

Ethylene dichloride (EDC), also known as 1,2-dichloroethylene, is a high use chemical in today's industry, for the synthesis of vinyl chloride, as a chlorinated solvent, and as a constituent in paints, soaps, scouring compounds, and metal degreasers [1]. EDC has also been used as an extracting solvent for spices and other natural flavorings, including tobacco. The production of EDC in the United States was about 16 million tons in 1994 [1]. In Louisiana the total EDC discharge for 1987 to 1993 was greater than 15 million pounds [2].

EDC is a known mutagen requiring metabolic activation by glutathione conjugation. Glutathione-dependant metabolites, such as $S$-(2-chloroethyl) glutathione and $S$-(2-chloroethyl)- $L$-cysteine, spontaneously rearrange to form reactive episulfonium ions that react with nucleophilc sites on cellular macromolecules including DNA [3, 4]. The major DNA adduct formed from EDC is reported to be N7-ethyl-S-glutathionyl deoxyguanosine $[3,5]$. Interestingly, the mutation spectrum produced by EDC and other dihaloethanes appears to be limited to $\mathrm{G} \rightarrow \mathrm{A}$ transitions [5]. Since most tissues contain glutathione and glutathione- $S$-transferase, EDC may react and damage multiple organs systems including testis. The US EPA has designated EDC as a potential carcinogen, hazardous substance, and priority toxic pollutant [6]. EDC is also designated as a possible human carcinogen (Group 2B) by the International Agency for Cancer Research [7].

Early studies with EDC have reported little or no reproductive toxicity. Inhalation studies showed only embryo

*Address correspondence to this author at the Department of Environmental Sciences, 1279 Energy, Coast \& Environment Bldg., Louisiana State University, Baton Rouge, LA 70803, USA; Tel: (225) 578-1753; Fax: (225) 578-4286; E-mail: Monster77@aol.com toxicity at high doses and no significant reproductive toxicity [8]. Rats and mice exposed to this highly volatile compound in drinking water or in diet showed no effects on fertility [9, 10] and lacked remarkable pathology in reproductive tissues [11].

These reports of limited reproductive and testicular toxicity by EDC are surprising since tissues with significant mitotic indexes are generally sensitive to reactive alkylating compounds, such as the activated EDC-glutathione episulfonium ion. Mammalian gonadal tissues are well known to be sensitive to cytotoxic agents. The loss of fertility in males due to chemotherapy has been well documented [12-15]. The present study was undertaken to evaluate the effects intraperitoneal EDC on the fertility and testicular tissue in male mice.

\section{MATERIAL AND METHODS}

\section{Animals}

Ten-week old male C57BL/6 mice were purchased from Charles River Laboratories Inc. (Wilmington, MA). The mice were housed in an animal core facility in a controlled temperature $\left(22^{\circ} \mathrm{C}\right)$ and humidity $(50 \%-60 \%)$ environment with greater than 10 complete exchanges of filtered air per hour. Mice were also on a $12 \mathrm{hr}$ light/dark cycle, and were fed autoclaved commercial mouse chow (Purina Autoclavable Laboratory Chow 5010, Ralston-Purina, St. Louis, MO) ad libitum. Males were housed four or five to a cage during acclimatization, and then one to a cage at the beginning of the experiment. As excellent breeders with C57BL/6 males, female Balb/c mice were obtained from the LSU School of Veterinary Medicine Animal Core Facility's breeding colony, and paired with males for fertility determinations. 
EDC (CAS No. 107-06-2) (99.8\%) was purchased from Sigma-Aldrich (St. Louis, MO). Each solution of EDC in corn oil was prepared fresh daily at concentrations necessary for intraperitoneal (IP) injections of $0.1 \mathrm{ml}$ per $10 \mathrm{~g}$ mouse weight. Sexually mature (greater than 11 weeks of age) male C57BL/6 mice received five IP injections, one per day for five consecutive days (Fig. 1). Fertility determinations utilized groups of three male mice per dose reported. With each IP injection, mice received a dose of 5 to $40 \mathrm{mg} / \mathrm{kg}$ of EDC or vehicle. Short-term doses of $40 \mathrm{mg} \mathrm{EDC} / \mathrm{kg}$ and lower were not anticipated to produce substantial systemic toxicity in mice; $\mathrm{LD}_{50}$ for mice is reported to be $489 \mathrm{mg} / \mathrm{kg}$ of body weight [1].

Since spermatogenesis was active at the time treatment began, mice were held for 45 days after the end of the five day treatment to allow for complete turnover of spermatogenesis prior to testing for fertility [16] (Fig. 1). This experimental protocol was designed to enable the determination of the effects of EDC on the early stages of spermatogenesis without the interference of mature sperm or maturing sperm that may have been collected and retained in the caudal epididymides and vas deferens during and shortly after treatment.

After 45 days post IP treatment males were then paired with Balb/c females to determine fertility. Males were determined to be permanently sterile if found to be infertile for six months or longer. Permanently sterile males and male mice that recovered to fertility were euthanized by $\mathrm{CO}_{2}$ asphyxiation only after siring two consecutive litters (Fig. 1). Upon sacrifice, the testes and epididymides were surgically excised carefully to reduce crush artifact, and immersed in formalin for subsequent pathological and histological analyses.

A separate experiment designed to determine the early testicular pathological effects of EDC was performed with the same dosing protocol above using $10 \mathrm{mg} / \mathrm{kg}$. Controls received IP injections of the vehicle (corn oil) only. Following the five days of dosing, one to three male C57BL/6 mice were euthanized at each time interval post treatment of 8,15 , 31 , and 46 days, and the testicular pathology assessed.

\section{Pathology}

Hematoxylan and eosin stained sections of paraffin embedded, formalin fixed testis were analyzed for the total number of Sertoli cell-only (SCO) tubules, and Leydig cell counts, for each testis examined. Testes were routinely sectioned transversely through the sagittal axis to obtain the greatest area for histology. For percent SCO determinations, between 130 and 300 separate tubules (248 tubules per testis on average) in each testis preparation were examined for the presence or absence of spermatogenic cells (spermatogonia, spermatocytes, spermatids and spermatozoa) in addition to Sertoli cells. Large interstitial polygona, eosinophilic cells with vacuolated (lipid containing) cytoplasm and round vesicular nuclei were identified and counted as Leydig cells. Leydig cells were counted in five randomly chosen high power microscopic fields $\left(1.77 \mathrm{~mm}^{2}\right)$ and the average normalized to the cross-sectional area of the testis using the formula for area of (1/4) $\pi \mathrm{D} 1 \mathrm{D} 2$, where $\mathrm{D} 1$ and $\mathrm{D} 2$ represent the perpendicular diameters, respectively. Due to laboratory processing error, the excised testes from the 20 and 40 $\mathrm{mg} / \mathrm{kg}$ dose mice were destroyed and unavailable for histological analyses.

Individual testes were also given a Spermatogenesis Score. The scoring system published by Johnsen [17] is based on human testicular evaluation. Mouse spermatogenic stages are arranged in relatively linear manner compared to the helical pattern observed in humans. However, the random evaluation of twenty seminiferous tubules per histological testicular cross-section should normalize these species differences and provide an appropriate scoring system to compare changes in testicular functions. Using the criteria of Johnsen [17] as modified by Aafjes et al. [18], hematoxylan and eosin stained sections of paraffin embedded, formalin fixed testis were scored on a 10 point scale assessing the extent of spermatogenesis. Twenty randomly chosen seminiferous tubules were evaluated utilizing the testicular scoring protocol below:

\section{0: Complete spermatogenesis}

9: Many spermatozoa present, but germinal epithelium disorganized with marked sloughing or obliteration of lumen

8: All stages of spermatogenesis present, but fewer than 5-10 spermatozoa present

7: No spermatozoa, but many spermatids present

6: No spermatozoa, but fewer than 5-10 spermatids present

5: No spermatozoa, no spermatids, but many spermatocytes present

4: No spermatozoa, no spermatids, but fewer than 5 spermatocytes present

3: Only spermatogonia present

2: Sertoli cells only

1: No cells in tubular cross section.

\section{Statistical Analysis}

Statistical analysis was performed using the one-way ANOVA, Fisher F-test for comparisons of three groups, and unpaired, two-tailed $t$ test for differences between treated and

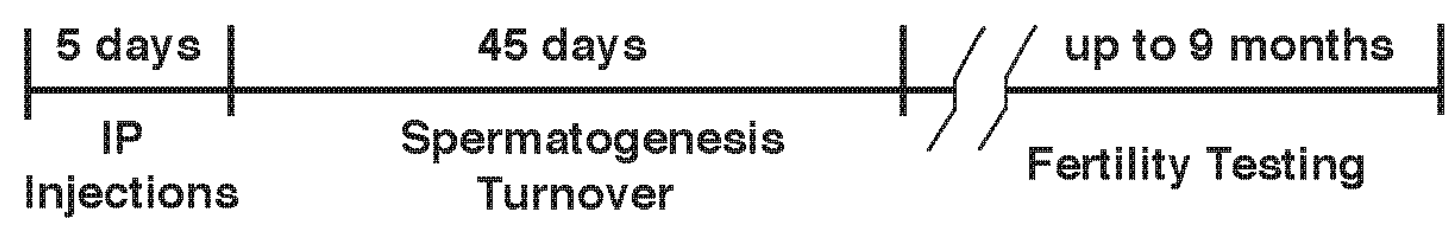

Fig. (1). Flow chart for experimental treatment and fertility testing of mice. Sexually mature male mice received 5 IP injections, one a day for 5 days, and then allowed to rest for 45 days for complete spermatogenesis turnover. Males were then housed with female mice to establish fertility. Mice were euthanized after siring 2 consecutive litters of pups or after found to be sterile for 6 months or longer. 
control percentages of SCO tubules, Leydig cell counts and testis cross-sectional areas, where the variance were not equal. The criterion for significance for all tests was $\mathrm{P} \leq$ 0.05 .

\section{RESULTS}

Following the protocol shown in Fig. (1), sexually mature male C57BL/6 mice were treated with IP injections of EDC and the subsequent fertility status of the mice evaluated (Table 1). In the present studies, mice treated with IP injections of EDC showed no obvious toxicity even at the 40 $\mathrm{mg} / \mathrm{kg}$ dose. Weight gain was consistent and matched controls throughout treatment time period and throughout the study. No loss of hair or any obvious lesions were noticed. Treated mice appeared normal with no sign of disorientation or lethargic behavior. These treated mice maintained a healthy normal appearance for the rest of the study, with the exception of one mouse $(10 \mathrm{mg} / \mathrm{kg}$ dose $)$ that died during week 13 post treatment of undetermined cause. A gross survey of organs and tissues did not discern an obvious cause of death or other notable injuries attributable to the EDC treatment.

After 45 days post EDC treatment, males were paired with female mice to determine fertility (Fig. 1). Unexpectedly, one male from each of the $20 \mathrm{mg} / \mathrm{kg}$ and $5 \mathrm{mg} / \mathrm{kg}$ groups sired a litter of six offspring immediately after being paired with female mice and were subsequently found to be permanently sterile or sterile for a brief period, respectively (see Table 1). The $5 \mathrm{mg} \mathrm{EDC} / \mathrm{kg}$ treatment group was the only dosing group where mice recovered to fertility after a brief sterile period (Table $\mathbf{1}$ ).

Male mice were euthanized by $\mathrm{CO}_{2}$ asphyxiation after siring two consecutive litters or determined to be permanently sterile. For all mice, gross examination of liver, brain and kidney tissues showed no obvious effects from EDC. Testicular tissue was examined for 0,5 , and $10 \mathrm{mg} / \mathrm{kg}$ doses. The testes were atrophic and the epididymides were shrunken and deflated in the sterile mice sacrificed at 270 days post treatment, for both EDC dose levels of 5 and 10 $\mathrm{mg} / \mathrm{kg}$. Histological analyses consistently displayed hypocellular tubules lacking spermatocytes and spermatogonia, and prominent vacuolization including Sertoli cells, while Leydig cells were evident (Fig. 2).

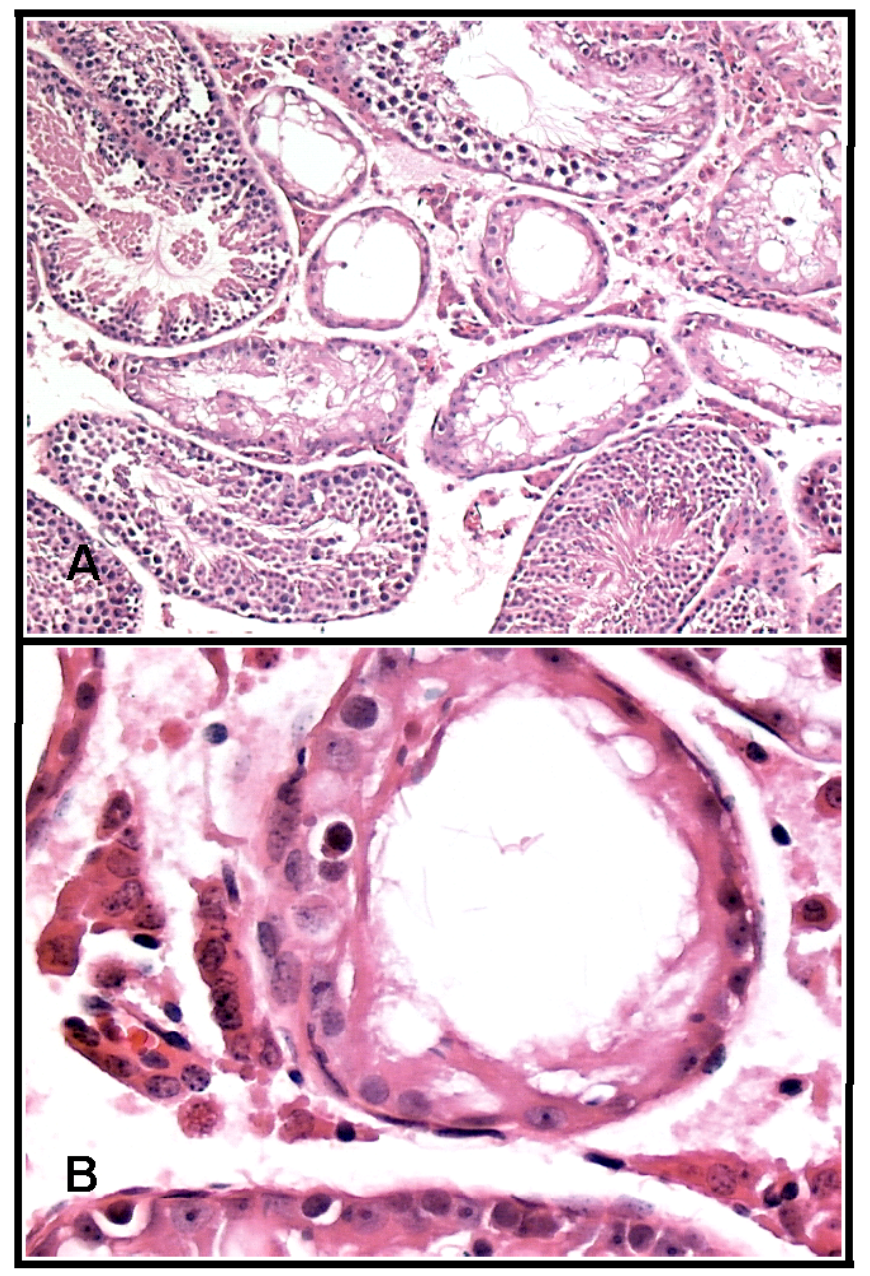

Fig. (2). Testis histological sections from a mouse determined to be sterile for 9 months following treatment with $5 \mathrm{mg}$ EDC/kg. (A) Section at 100x magnification, this section displays the disruption of interstitial collagenous tissue, preservation of Leydig cells and loss of spermatogonia in many tubules, where vacuolization is prominent, signifying cellular damage. (B) At 400x magnification, this tubule shows rare spermatogonia and vacuolar change of Sertoli cells; note the intact Leydig cells adjacent to the tubule.

A more promising testicular pathology was observed from the two males treated with $5 \mathrm{mg}$ EDC/ $\mathrm{kg}$ that recovered

Table 1. Fertility Results in Mice Exposed to EDC

\begin{tabular}{|c|l|}
\hline Dosage $^{\mathbf{a}}(\mathbf{m g} / \mathbf{K g})$ & \\
\hline \hline 0 & None (Fertile) \\
\hline 5 & $\begin{array}{l}3 \text { weeks (one mouse), } \\
5 \text { weeks (one mouse), } \\
\text { Permanently Sterile (one mouse), sterile for } 270 \text { days post treatment }\end{array}$ \\
\hline 10 & Permanently Sterile (2 mice $\left.{ }^{\text {c }}\right)$, sterile for 270 days post treatment \\
\hline 20 & Permanently Sterile (all 3 mice), sterile for 180 days post treatment \\
\hline 40 & Permanently Sterile (all 3 mice), sterile for 180 days post treatment \\
\hline
\end{tabular}

${ }^{a}$ Three mice per dose group, except for control (zero dose, corn oil only) which contained four mice. Each male mouse received 5 ip doses, one per day for 5 days.

${ }^{\mathrm{b}}$ Following a 45 day post treatment holding time, male mice were housed with fertile female mice until determined to be fertile or permanently sterile (see Materials and Methods). 'One mouse died during week 13 of unknown causes (see text). 
to fertility after a 3 and 5 week sterile period, respectively, prior to sacrifice at 120 days (see Table 1). Histological analyses of testes from fertility-recovered males displayed active spermatogenesis among tubules with pleomorphism and hyperchromasia of spermatocytes and spermatogonia as compared to controls (Fig. 3). Other tubules displayed disruption of spermatogenesis and significant apoptotic processes.

In a separate short-term study with $10 \mathrm{mg} \mathrm{EDC} / \mathrm{kg}$, treatment induced adverse pathology was evident as early as 8 days post treatment (Fig. 4). It appears that EDC may have induced an arrest in spermatogenesis with subsequently developing tubular germ cell aplasia within 8 days. Tubular damage, marked vacuolization of cells and loss of spermatogonia was detectable at 8 days and deteriorated with longer time periods post dose (Figs. 2, 3 and 4). However, Leydig and Sertoli cells were consistently present in these histology sections.

As indicators of testicular pathology, histologic preparations from mouse testes were examined for Leydig cell counts, percentage of seminiferous tubules that are SCO, and scored based on spermatogenic activity $[17,18]$. Analyses of testicular tissue from all of the mice treated with EDC displayed numerous Leydig cells in the intertubular interstitial spaces. A dose response effect of EDC treatment on
Leydig cell numbers was not observed. An ANOVA comparison of the Leydig cell counts from the three treatment groups based on dose (zero, $5 \mathrm{mg} / \mathrm{Kg}$, and $10 \mathrm{mg} / \mathrm{Kg}$ ), provided a borderline significant difference (Table 2), but the results were complicated by an increase in Leydig cells with the $5 \mathrm{mg} / \mathrm{Kg}$ dose and a decrease with the $10 \mathrm{mg} / \mathrm{Kg}$ dose, neither of which were individually statistically significant. However, the analyses of Leydig cell numbers may have been complicated by swelling of the testes in EDC treated mice. Although not significant by ANOVA analysis, the testis cross-sectional area appears to increase with increasing doses of EDC (Table 2). The $10 \mathrm{mg} / \mathrm{Kg}$ treatment group displayed a significant increase in cross-sectional area compared with controls (Table 2), as did the combined groups of EDC treated mice $(5 \mathrm{mg} / \mathrm{Kg}+10 \mathrm{mg} / \mathrm{Kg}$ groups $)$ compared with controls $(20.52 \pm 4.55(\mathrm{n}=11) ; \mathrm{P}<0.038)$.

When these results are compared based on time post treatment, testicular preparations from EDC treated mice sacrificed equal to or greater than 120 days contained more Leydig cells, but not significantly, than preparations from EDC treated mice sacrificed less than or equal to 46 days $(2.65 \pm 0.89(\mathrm{n}=5)$ vs. $1.76 \pm 0.46(\mathrm{n}=6) ; \mathrm{P}<0.061)$, and from control mice $(2.29 \pm 0.34(\mathrm{n}=8) ; \mathrm{P}<0.319)$. Interestingly, the cross-sectional area was significantly increased in the mice sacrificed greater than or equal to 120 days over

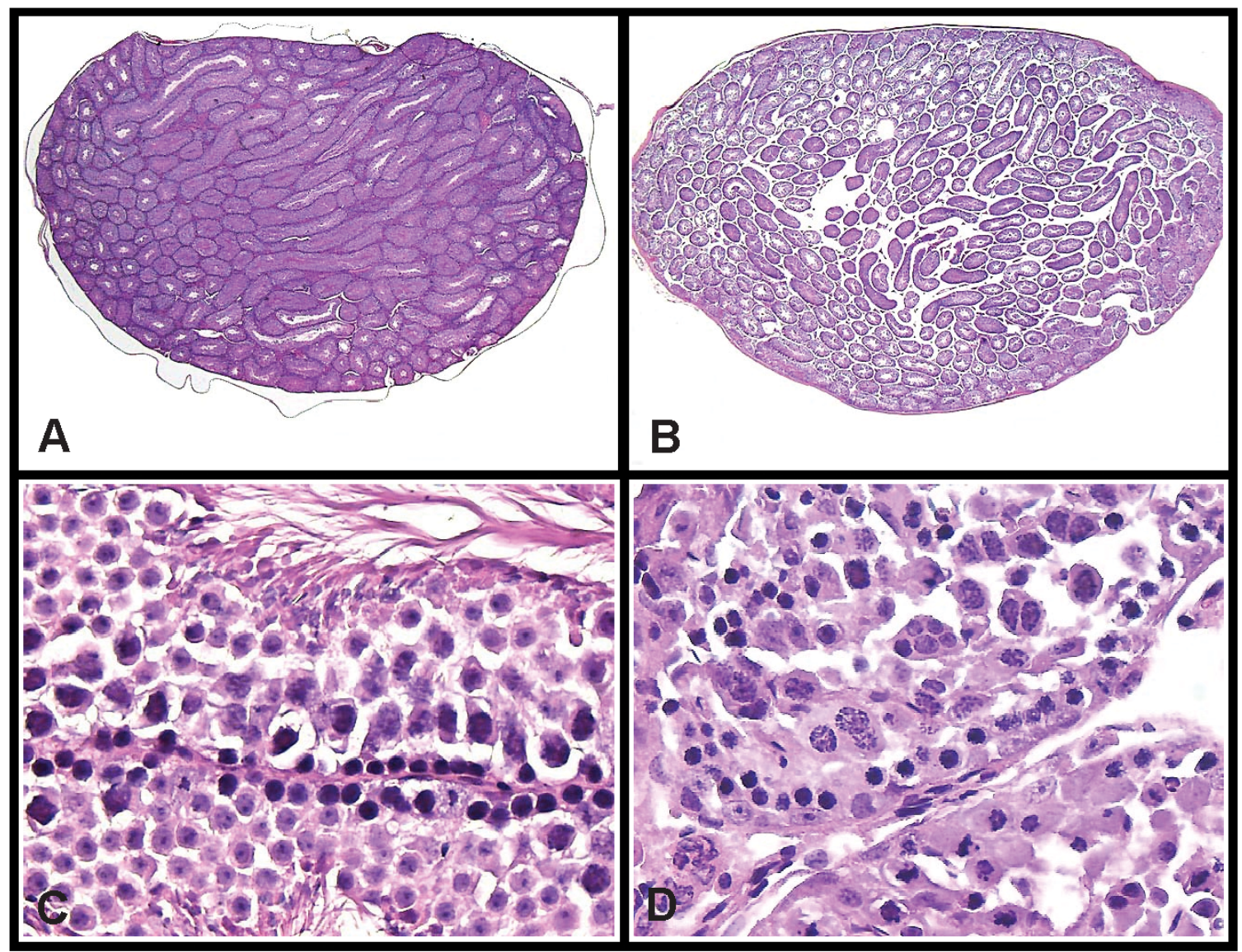

Fig. (3). Testis histological sections from (A \& C) normal control ( $0 \mathrm{mg} / \mathrm{kg})$ mouse, and (B \& D) $5 \mathrm{mg} / \mathrm{kg}$ treated mouse that recovered to fertility following a sterile period of 5 weeks, exhibiting noticeable differences in spermatogenesis. Note on scanning magnification the loss of cellularity, loss of adhesion amongst the tubules and interstitial tissue, and increased number of dilated seminferous tubules in the EDC treated mouse (B) compared to the densely packed seminferous tubules of the normal control mouse (A) (20x magnification). At 400x magnification, the normal control mouse shows complete, organized spermatogenesis with numerous spermatozoa (C); whereas, the EDC treated mouse shows disruption of spermatogenesis with loss of spermatozoa and spermatids, and scattered apoptotic bodies (D). 
Table 2. Leydig Cell Counts and Testis Cross-Sectional Areas in Mice Exposed to EDC

\begin{tabular}{|c|c|c|c|c|c|}
\hline & $\begin{array}{l}\text { Zero mg / Kg } \\
\text { (Controls) }\end{array}$ & $\begin{array}{l}5 \mathrm{mg} / \mathrm{Kg} \\
\mathrm{EDC}\end{array}$ & $\begin{array}{l}10 \mathrm{mg} / \mathrm{Kg} \\
\mathrm{EDC}\end{array}$ & $\begin{array}{l}\text { P value }^{a} \\
\text { (group) }\end{array}$ & $\begin{array}{c}\text { P value }^{\mathrm{b}} \\
\text { (Individual Comparisons) }^{\text {Col }}\end{array}$ \\
\hline Leydig Cells ${ }^{c}$ & $2.29 \pm 0.35(8)^{d}$ & $2.90 \pm 1.15(3)$ & $1.89 \pm 0.47(8)$ & 0.050 & $0.183 / 0.068 / 0.057$ \\
\hline $\begin{array}{c}\text { Testes } \\
\text { Cross Sectional Area }\left(\mathrm{mm}^{2}\right)^{\mathrm{e}}\end{array}$ & $16.78 \pm 1.26(8)$ & $18.87 \pm 4.56$ & $21.14 \pm 4.69(8)$ & 0.136 & $0.234 / \mathbf{0 . 0 2 4} / 0.546$ \\
\hline
\end{tabular}

Bold: significant difference at $\mathrm{P}<0.05$. Italics weak significance $\mathrm{P}<0.1$.

${ }^{a}$ ANOVA Fisher F-test of the three data sets, including control, $5 \mathrm{mg} / \mathrm{Kg}$, and $10 \mathrm{mg} / \mathrm{Kg}$

${ }^{\mathrm{b}}$ Comparisons between groups - Control vs. $5 \mathrm{mg} / \mathrm{Kg} /$ Control vs. $10 \mathrm{mg} / \mathrm{Kg} / 5 \mathrm{mg} / \mathrm{Kg}$ vs. $10 \mathrm{mg} / \mathrm{Kg}$.

${ }^{c}$ Average number of Leydig cells present in five randomly chosen high powered microscopic fields normalized per testis cross-sectional area $\left(\right.$ Leydig cells per mm $\left.{ }^{2}\right)$.

${ }^{\mathrm{d}}$ Mean \pm standard deviation, (number of mice analyzed).

${ }^{\mathrm{e}}$ Average testis cross-sectional area $\left(\mathrm{mm}^{2}\right)$ (see Materials and Methods).

controls $(20.18 \pm 3.77(\mathrm{n}=5)$ vs. $16.78 \pm 1.26(\mathrm{n}=8) ; \mathrm{P}<$ $0.035)$, but not over EDC treated mice sacrificed less than or equal to 46 days $(20.80 \pm 5.46(\mathrm{n}=6) ; \mathrm{P}<0.835)$. As these mouse experiments were established for clinical fertility determinations, none of the control mice were carried out to

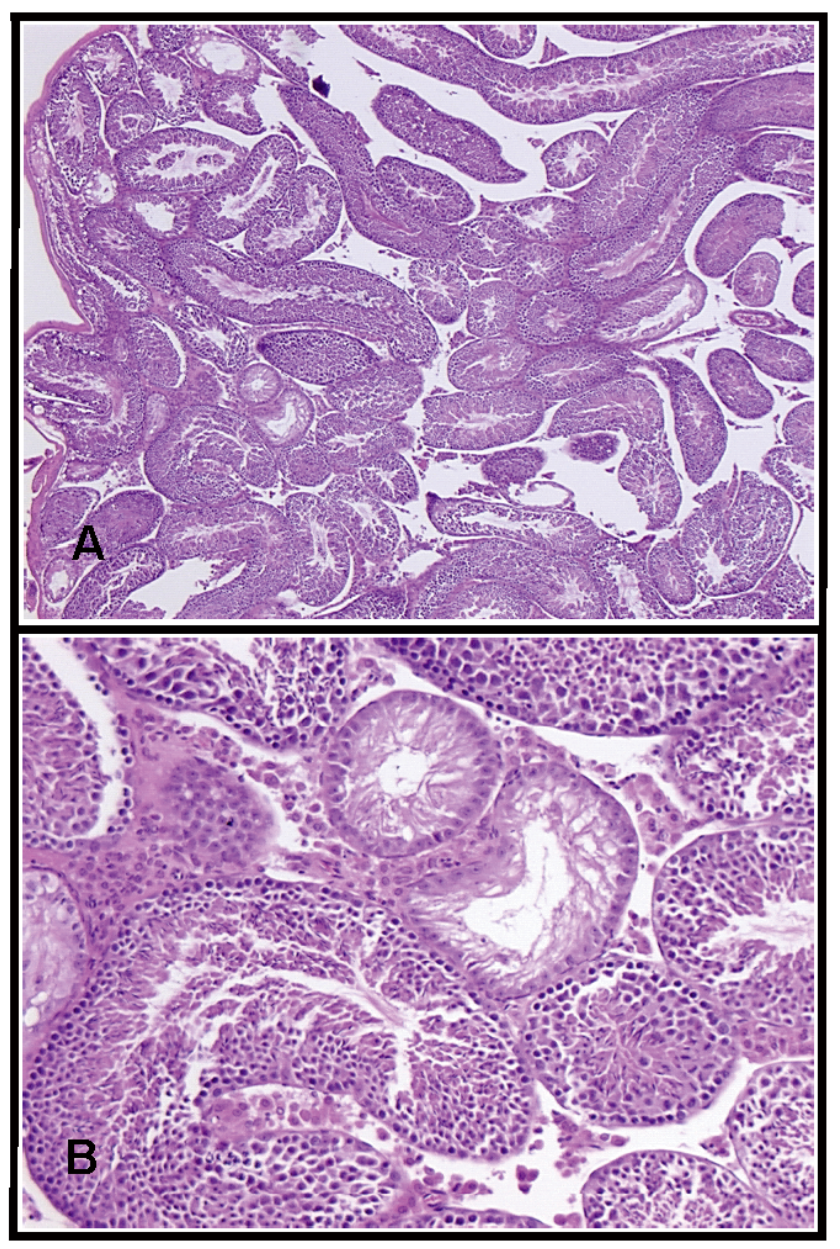

Fig. (4). Testis histological sections from a $10 \mathrm{mg}$ EDC/kg mouse euthanized only 8 days after treatment. (A) Section at 100x magnification, sections display tubular damage and disruption of testicular structure. (B) At 200x magnification, two central Sertoli CellOnly tubules show marked vacuolization (and loss of spermatogonia).
120 days or longer. Control Leydig cell counts ranged from 1.82 to 2.45 , which was similar to the less than or equal to 46 day EDC treated mice.

Sertoli cells also appeared to be resilient to the damaging effects of EDC as these cells were consistently present in testicular preparations from all of the treated mice. Seminiferous tubules from each testis were analyzed for the presence of Sertoli cells and the loss of developing spermatogonia and spermatozoa, providing the recorded result of percent of the tubules that are SCO. By an ANOVA analysis, a significant dose response effect of increasing SCO tubules $(\mathrm{P}=0.043)$ and decreasing testis score was observed $(\mathrm{P}=$ 0.0001) (Fig. 5). Testicular preparations from both 5 and 10 $\mathrm{mg} / \mathrm{kg}$ EDC treatment groups displayed significantly more SCO tubules than controls $(\mathrm{P}<0.04$ and $\mathrm{P}<0.0002$, respectively) (Fig. 5). Testes from mice treated with $5 \mathrm{mg}$ EDC/kg ranged from $2 \%$ to $36 \% \mathrm{SCO}$, the $36 \%$ corresponding to the one mouse at this dose that was found to be permanently sterile, while the controls ranged from $0 \%$ to $4 \%$ SCO. Similarly, testes from mice treated with EDC at $10 \mathrm{mg} / \mathrm{kg}$ ranged from $7 \%$ to $22 \%$, with the highest values corresponding to mice euthanized after 270 days, suggesting a time post treatment effect. Testicular preparations obtained from mice treated with EDC and euthanized 120 days or later harbored significantly more SCO tubules than EDC treated mice sacrificed less than 120 days $(22.8 \pm 11.9$ ( $\mathrm{n}=5)$ vs. $8.67 \pm 1.63$ $(\mathrm{n}=6) ; \mathrm{P}<0.017)$. However, both of these EDC treatment groups were significantly different than controls $(1.56 \pm 1.52$ $(\mathrm{n}=8) ; \mathrm{P}<0.0003$ and $\mathrm{P}<0.0001$, respectively), even though the controls were sacrificed in the same time frame as the latter EDC treated group, less than 120 days post treatment. The impact of $10 \mathrm{mg} / \mathrm{kg}$ of EDC treatment was observable as early as 8 days post treatment with the testis displaying $7 \%$ SCO tubules (Figs. 4 and 5). Interestingly, testicular damage remained at a similar level throughout a 46-day post treatment time course, as testes obtained from EDC treated males 15,31 and 46 days post $10 \mathrm{mg} / \mathrm{kg}$ dose displayed $7 \%$ to $11 \%$ SCO tubules.

EDC induced adverse pathology was evident within 8 days post dose and reached a plateau throughout 15 to 46 days. Using the standard methods for the evaluation of cellular activities and structural integrity, testes were given a pathology score. As early as 8 days post treatment with 10 $\mathrm{mg} / \mathrm{kg}$ of EDC the testis displayed a reduced score of 8.35 (Fig. 4). Controls provided testicular pathology scores ranging from 8.85 to 9.85 (average 9.46). Testes obtained from 
males 15 to 46 days post $10 \mathrm{mg} / \mathrm{kg}$ treatment displayed scores ranging from 6.40 to 7.40 , which were similar to the scores of sterile males $(10 \mathrm{mg} / \mathrm{kg}$ dose) carried for 9 months (270 days). Comparing all testicular specimens together demonstrated a direct response to EDC and decreased spermatogenesis (Fig. 5). The testis score decreased significantly with EDC doses of 5 and $10 \mathrm{mg} / \mathrm{kg}(\mathrm{P}<0.0001)$ compared to controls. The time course of the effect on testicular damage and the testis score is clearly displayed in a Spline curve of the combined 5 and $10 \mathrm{mg} / \mathrm{kg}$ treatment groups (Fig. 6).

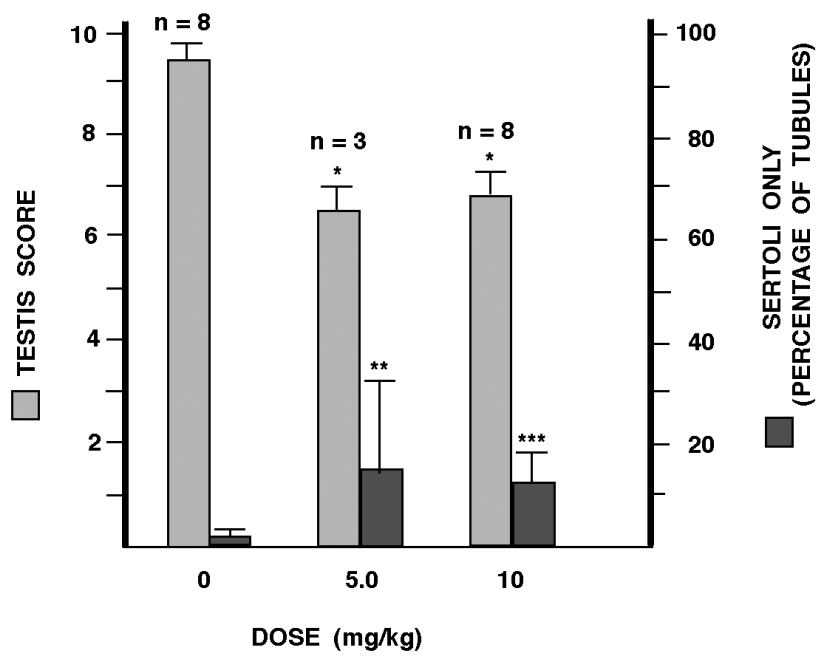

Fig. (5). Dose response effects of EDC on testicular pathology. The Testes Score (light grey) decreased with EDC treatment (ANOVA, $\mathrm{P}<0.0001$ ), while the percentage of tubules that only contained Sertoli cells (dark grey) increased (ANOVA, $\mathrm{P}<0.016$ ). The time post treatment that testes were harvested from mice following euthanization ranged from 8 to 270 days. Two of the mice in the 5 $\mathrm{mg} / \mathrm{kg}$ EDC treatment group recovered fertility prior to harvest at 120 days. The number (n) of testes (one per male mouse) in each treatment group is denoted above the bars. A single asterisk (*) indicates that the Testis Scores for the 5 and $10 \mathrm{mg} / \mathrm{kg}$ EDC treatment groups were significantly different $(\mathrm{p}<0.0001)$ from controls $(0 \mathrm{mg} / \mathrm{kg}$ EDC). A double asterisk $(* *)$ and triple asterisk $(* * *)$ indicates that the percent of SCO tubules were significantly elevated $(\mathrm{P}<0.04$ and $\mathrm{P}<0.0002$, respectively) from controls.

\section{DISCUSSION}

Reproductive toxicity has not been previously associated with EDC, a heavily used industrial chemical [1, 19]. The present experimental results suggest that EDC may potentially affect the mammalian testes resulting in partial loss of germ cells and decreased fertility. Short-term IP doses of 10 $\mathrm{mg} \mathrm{EDC} / \mathrm{kg}$, daily for five days, rendered male C57BL/6 mice sterile for at least 9 months. Previous reports on the lack of reproductive toxicity utilized drinking water and diet as a route of exposure [8-11]. It is possible that the concentrations of EDC in the food and water were over estimated due to the high volatility of this compound. Alternatively, the intraperitoneal injection route may bias the distribution of EDC in such a way as to enhance the concentrations of EDC that reach the testes. Further studies will be necessary to clarify these issues and to determine the presence of any reproductive health risks to mammals or humans from EDC by other routes of exposure.
The sensitivity of the mammalian testis and germ cells to EDC may also be a function of the dose-rate due to the accumulation of damage produced by each daily exposure [20]. The sensitivity of the human testis to the toxic effects of EDC as compared to the mouse is not currently known, although infertility-inducing doses of chemotherapeutic drugs are similar in man and mouse $[12,21]$.

Activation of EDC occurs by glutathione conjugation, producing a highly reactive episulfonium ion $[3,5]$. With the possible exception of the latter stages of maturing germ cells, most of the cells of the testes contain glutathione and express one or more glutathione- $S$-transferases, so that EDC is readily activated in the testes. The testicular toxic impact of EDC could result from targeting germ cells, Sertoli cells or Leydig cells. The sensitivity of germ cells to the direct actions of alkylating agents depends on the stage of maturation, such that dividing pre-meiotic spermatogonia may be much more susceptible to lethal effects of EDC than post-meiotic spermatids which no longer actively replicate DNA, are repairdeficient, and begin to condense chromatin. Alternatively, disruption of the Sertoli cell function by EDC may lead to a precipitous and persistent loss of germ cells. Diminished production of cytokines and other factors (e.g. leukemia inhibitory factor (LIF) and bone morphogenic protein-4 (BMP4)) will lead to spermatogonial stem cells losing their self-replacement character and becoming committed spermatogonia cells [22-25]. Early differentiation committed germ cells, spermatogonia A1 - A4 stages and above, require stem cell factor (SCF) and the nurturing of selective seminiferous fluid constituents produced by Sertoli cells near the basal membrane of the seminiferous tubule [26, 27]. Adhesion proteins specific for Sertoli cell-germ cell attachment may also be required for germ cell survival and maturation [28]. Disturbing Leydig cell testosterone production may perturb the hypothalamic-pituitary-testis axis and gonadotropic hormone balance, leading to loss of spermatogenesis and testicular atrophy [29]. The continued presence and health of Leydig cells in atrophic testes from sterile mice argues against this mode of action by EDC. Although Leydig cell count analyses were complicated by changes in crosssectional size of the testes, a potential Leydig cell hyperplasia was suggested after 6 months time post EDC treatment. Leydig cell hyperplasia has been reported in response to other alkylating agents and may be the result of indirect long-term hormonal feedback due to limited or lack of spermatogenesis in the testes [30, 31]. However, the present results are equivocal and further experimental analyses of the effects of EDC on Leydig cells needs to be performed.

The present experimental results demonstrated the survival of both Sertoli cells and Leydig cells despite persistent and prolonged testicular damage initiated by EDC. This suggests that if either of these two cell types was targeted by EDC, the greatest impact was on Sertoli cellular function and the subsequent loss of maintenance and maturation of germ cells. Based on testicular pathology, the damage induced by EDC was complete within the first 8 days. This protracted atrophic effect on spermatogenesis was most likely due to a significant loss of required factors and the environmental niche of seminiferous fluid constituents, and/or close Sertoli cell-germ cell association. Lack of maintenance of spermatogonial stem cells as self-replacing germ stem cells would lead to an ultimate loss of germ cells, since 


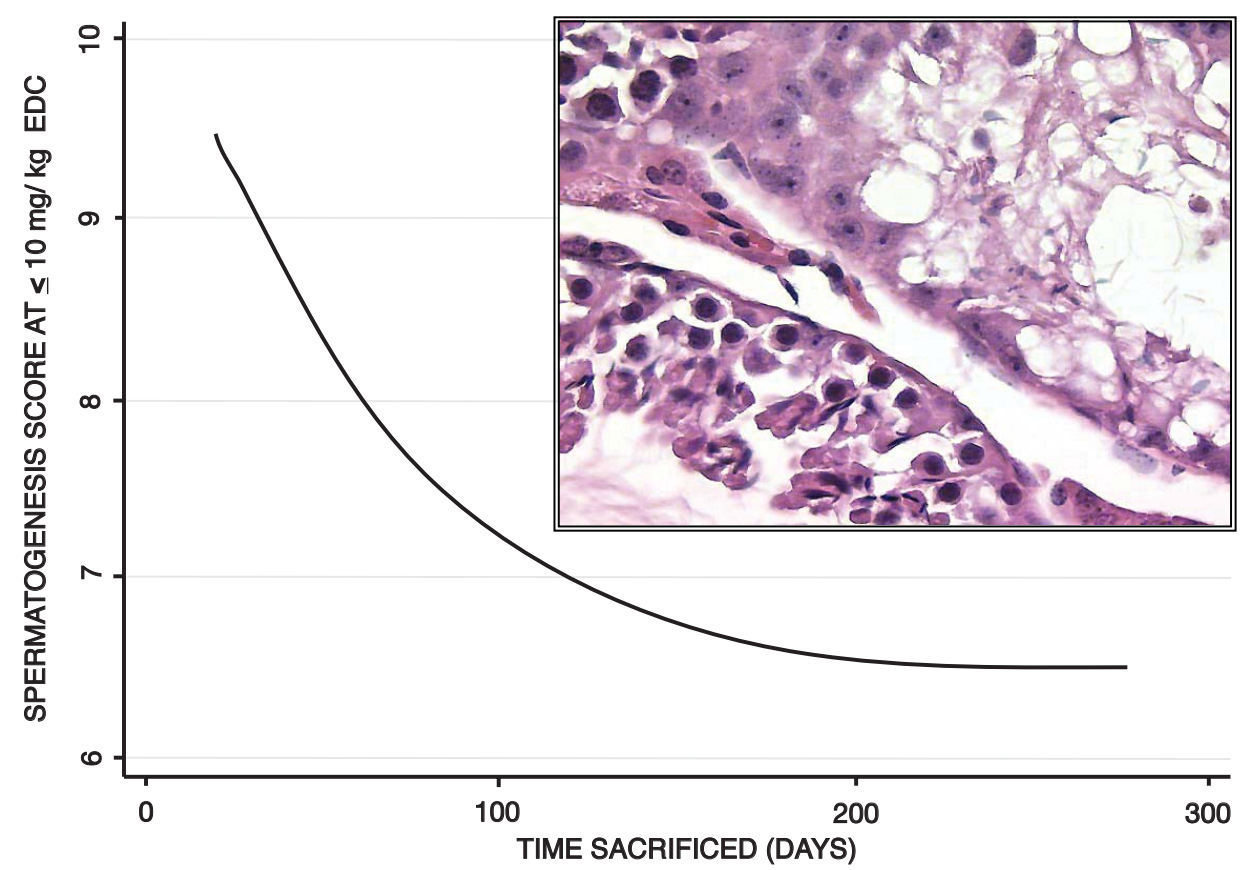

Fig. (6). Spline curve demonstrating the effect of EDC on spermatogenesis over time. Spline curve was derived from the combined data of both $5 \mathrm{mg} / \mathrm{kg}$ and $10 \mathrm{mg} / \mathrm{kg}$ treated mice. This is a median Spline curve calculated by obtaining cross medians, which are used as knots to fit a cubic spline that is graphed as line plot. Insert photo shows two seminferous tubules from a $5 \mathrm{mg} / \mathrm{kg}$ treated mouse that was sacrificed at 120 days, one (top) with sloughed necrotic material and spermatogonia only (score 3), and the other (bottom) with few spermatozoa and all stages of spermatogenesis (score 8 ).

spermatogonial stem cells would become differentiation committed spermatogonia A1 or B cells. The result is the same whether increased apoptotic pressure induced loss of germ cells during maturation, or by direct lethal alkylation damage to stem cells. However, spermatogonial stem cells have a slow cell cycle rate of 8 or more days in the testes, allowing time for significant DNA repair prior to DNA replication and division, making direct cell killing by EDC alkylation less likely $[14,32]$. It is possible that the careful determination of which stage(s) of spermatogonia are initially diminished by EDC may provide more clarification of the mechanism by which EDC disrupts spermatogenesis.

Doses of EDC at $5 \mathrm{mg} / \mathrm{kg}$ produced sterile periods of several weeks in two of three treated male mice, suggesting that recovery and repopulation of the seminiferous tubules with spermatogonial stem cells is possible at lower doses. Similar dose-dependent recovery of spermatogenesis in mice has been described for cis-platinum [33], neutron radiation [34], 2.5-hexanedione [35], mono-2-ethylhexyl phthalate [36], and in humans treated with chemotherapeutic agents [14].

EDC is a potent mutagen and could initiate mutations in replicating germ cells. The closely related compound, 2-chloroethyl methanesulfonate, that also forms the same structural DNA adducts as EDC via an episulfonium ion following activation by glutathione, has been shown to be a potent germ cell mutagen in Drosophila melanogaster [37, 38]. Germ line mutagenesis has been demonstrated for 2bromoethane and EDC in Drosophila [39]. It is also interesting to note that two offspring in the last litter sired by one of the fertility-recovered males ( $5 \mathrm{mg} / \mathrm{kg}$ group) were severely deformed. However, the potential risk for EDC initiated increases in germ line mutagenesis in humans is unknown and perhaps less probable [40].
The present study suggests that EDC administered IP is toxic to the testes and spermatogenesis in mice. Similar testicular toxicity might well be a property of the class of dihaloethanes. More research is needed to determine the mode of disruption of spermatogenesis, loss of germ stem cells and protracted testicular damage, as well as the impact of the route of exposure on this testicular toxicity. Titration of the dose of EDC used in this 5-day treatment regimen enabling fertility-recovery and expansion of surviving spermatogonial stem cells may provide an additional model for the study of germ cells at all stages of maturation and their susceptibilities to toxic actions of chemicals. With the progressive loss of spermatogonia, but not the Sertoli cells from tubules, the pathology has similarities to the testicular dysgenesis syndrome in the human clinic [41], and possibly to a nonheritable, environmentally acquired Sertoli CellOnly Syndrome [42].

\section{ABBREVIATIONS \\ $\mathrm{EDC}=$ Ethylene dichloride \\ SCO = Sertoli cell-only}

\section{REFERENCES}

[1] ATSDR. Toxicological Profile for 1,2-Dichloroethane. Agency for Toxic Substances and Disease Registry, US Department of Health and Human Services. Atlanta: GA 2001.

[2] LDEQ. The 1993 Louisiana Toxics Release Inventory, Louisiana Department of Environmental Quality. Baton Rouge: LA 1995; p. 52.

[3] Romert L, Magnusson J, Ramel C. The importance of glutathione and glutathione transferase for somatic mutations in Drosophila melanogaster induced in vivo by 1, 2-dichloroethane. Carcinogenesis 1990; 11(8): 1399-402.

[4] Peterson LA, Harris TM, Guengerich FP. Evidence for an episulfonium ion intermediate in the formation of S-[2-(N7-guanyl)- 
ethyl]glutathione in DNA. J Am Chem Soc 1988; 110(10): 328491.

[5] Cmarik JL, Humphreys WG, Bruner KL, Lloyd RS, Tibbetts C, Guengerich FP. Mutation spectrum and sequence alkylation selectivity resulting from modification of bacteriophage M13mp18 DNA with S-(2-chloroethyl)glutathione. Evidence for a role of S(2-N7-guanyl)ethyl)glutathione as a mutagenic lesion formed from ethylene dibromide. J Biol Chem1992; 267(10): 6672-9.

[6] USEPA. Ethylene Dichloride (1,2-Dichloroethane): Hazard Summary. U.S. Environmental Protection Agency: Washington, DC 2001, http://www.epa.gov/ttn/atw/hlthef/di-ethan.html

[7] IARC. Monographs on the Evaluation for Carcinogenic Risk to Humans. Complete List of Agents Evaluated and Their Classification. International Agency for Research on Cancer 2006, http:// monographs.iarc.fr/eng/classification/index.php

[8] Hurtt ME, Valentine R, Alvarez L. Developmental toxicity of inhaled trans-1, 2-dichloroethylene in the rat. Fundam Appl Toxicol 1993; 20(2): 225-30.

[9] Lane RW, Riddle BL, Borzelleca JF. Effects of 1,2-dichloroethane and 1,1,1-thichloroethane in drinking water on reproduction and development in mice. Toxicol Appl Pharmacol 1982; 63(3): 40921.

[10] Alumot E, Meidler M, Holstein P. Tolerance and acceptable daily intake of ethylene dichloride in the chicken diet. Food Cosmet Toxicol 1976; 14(2): 111-4.

[11] Daniel FB, Robinson M, Olson GR, York RG, Condie LW. Ten and ninety-day toxicity studies of 1,2-dichloroethane in SpragueDawley rats. Drug Chem Toxicol 1994; 17(4): 463-77.

[12] Meistrich ML. Effects of chemotherapy and radiotherapy on spermatogenesis. Eur Urol 1993; 23(1): 136-41; discussion 42.

[13] Meistrich ML, Samuels RC. Reduction in sperm levels after testicular irradiation of the mouse: a comparison with man. Radiat Res 1985; 102(1): 138-47.

[14] Meistrich ML. Stage-specific sensitivity of spermatogonia to different chemotherapeutic drugs. Biomed Pharmacother 1984; 38(3): 137-42.

[15] Chapman RM. Gonadal injury resulting from chemotherapy. Am J Ind Med 1983; 4(1-2): 149-61.

[16] Drost JB, Lee WR. Biological basis of germline mutation: comparisons of spontaneous germline mutation rates among drosophila, mouse, and human. Environ Mol Mutagen 1995; 25(Suppl 26): 4864.

[17] Johnsen SG. Testicular biopsy score count-a method for registration of spermatogenesis in human testes: normal values and results in 335 hypogonadal males. Hormones 1970; 1(1): 2-25.

[18] Aafjes JH, van der Vijver JC, Schenck PE. Value of a testicular biopsy rating for prognosis in oligozoospermia. Br Med J 1978; 1(6108): 289-90.

[19] WHO. 1,2-Dichloroethane. World Health Organization. Environmental Health Criteria Report, No. 62, 1987.

[20] Boekelheide K, Eveleth J. The rate of 2,5-hexanedione intoxication, not total dose, determines the extent of testicular injury and altered microtubule assembly in the rat. Toxicol Appl Pharmacol 1988; 94(1): 76-83.

[21] Seaman F, Sawhney P, Giammona CJ, Richburg JH. Cisplatininduced pulse of germ cell apoptosis precedes long-term elevated apoptotic rates in C57/BL/6 mouse testis. Apoptosis 2003; 8(1): 101-8.

[22] Ying QL, Nichols J, Chambers I, Smith A. BMP induction of Id proteins suppresses differentiation and sustains embryonic stem cell self-renewal in collaboration with STAT3. Cell 2003; 115(3): 281-92.

[23] Lacham-Kaplan O. In vivo and in vitro differentiation of male germ cells in the mouse. Reproduction 2004; 128(2):147-52.

[24] Pellegrini M, Grimaldi P, Rossi P, Geremia R, Dolci S. Developmental expression of BMP4/ALK3/SMAD5 signaling pathway in the mouse testis: a potential role of BMP4 in spermatogonia differentiation. J Cell Sci 2003; 116(Pt 16): 3363-72.
[25] Boekelheide K. Mechanisms of toxic damage to spermatogenesis. J Natl Cancer Inst Monogr 2005; 34: 6-8.

[26] Rossi P, Sette C, Dolci S, Geremia R. Role of c-kit in mammalian spermatogenesis. J Endocrinol Invest 2000; 23(9): 609-15.

[27] Sette C, Dolci S, Geremia R, Rossi P. The role of stem cell factor and of alternative c-kit gene products in the establishment, maintenance and function of germ cells. Int J Dev Biol 2000; 44(6): 599608.

[28] Beall SA, Boekelheide K, Johnson KJ. Hybrid GPCR/cadherin (Celsr) proteins in rat testis are expressed with cell type specificity and exhibit differential Sertoli cell-germ cell adhesion activity. J Androl 2005; 26(4): 529-38.

[29] Cook JC, Klinefelter GR, Hardisty JF, Sharpe RM, Foster PM. Rodent Leydig cell tumorigenesis: a review of the physiology, pathology, mechanisms, and relevance to humans. Crit Rev Toxicol 1999; 29(2): 169-261.

[30] Khalaj M, Abbasi AR, Nishimura R, et al. Leydig cell hyperplasia in an ENU-induced mutant mouse with germ cell depletion. J Reprod Dev 2008; 54(3): 225-8.

[31] Holm M, Rajpert-De Meyts E, Andersson AM, Skakkebaek NE. Leydig cell nicronodules are a common finding in testicular biopsies from men with impaired spermatogenesis and are associated with decreased testosterone/LH ratio. J Pathol 2003; 199(3): 37886.

[32] Schoenfeld HA, Hall SJ, Boekelheide K. Continuously proliferative stem germ cells partially repopulate the aged, atrophic rat testis after gonadotropin-releasing hormone agonist therapy. Biol Reprod 2001; 64(4): 1273-82.

[33] Pogach LM, Lee Y, Gould S, Giglio W, Meyenhofer M, Huang HF. Characterization of cis-platinum-induced Sertoli cell dysfunction in rodents. Toxicol Appl Pharmacol 1989; 98(2): 350-61.

[34] van Beek ME, Meistrich ML, de Rooij DG. Probability of selfrenewing divisions of spermatogonial stem cells in colonies, formed after fission neutron irradiation. Cell Tissue Kinet 1990; 23(1):1-16

[35] Boekelheide K. Rat testis during 2,5-hexanedione intoxication and recovery. I. Dose response and the reversibility of germ cell loss. Toxicol Appl Pharmacol 1988; 92(1):18-27.

[36] Richburg JH, Boekelheide K. Mono-(2-ethylhexyl) phthalate rapidly alters both Sertoli cell vimentin filaments and germ cell apoptosis in young rat testes. Toxicol Appl Pharmacol 1996; 137(1): 42-50.

[37] Fossett NG, Byrne BJ, Tucker AB, Arbour-Reily P, Chang S, Lee WR. Mutation spectrum of 2-chloroethyl methanesulfonate in Drosophila melanogaster premeiotic germ cells. Mutat Res 1995 331(2): 213-24.

[38] Fossett NG, Byrne BJ, Tucker AB, Arbour-Reily P, Chang S, Lee WR. Erratum to mutation spectrum of 2-chloroethyl methanesulfonate in Drosophila melanogaster premeiotic germ cells' [Mutation Res. 331 (1995) 213-224]. Mutat Res 1996; 354(1): 143-4.

[39] Kramers PG, Mout HC, Bissumbhar B, Mulder CR. Inhalation exposure in Drosophila mutagenesis assays: experiments with aliphatic halogenated hydrocarbons, with emphasis on the genetic activity profile of 1,2-dichloroethane. Mutat Res 1991; 252(1): 1733.

[40] Wyrobek AJ, Mulvihill JJ, Wassom JS, et al. Assessing human germ-cell mutagenesis in the Postgenome Era: a celebration of the legacy of William Lawson (Bill) Russell. Environ Mol Mutagen 2007; 48(2): 71-95.

[41] Skakkebaek NE, Rajpert-De Meyts E, Main KM. Testicular dysgenesis syndrome: an increasingly common developmental disorder with environmental aspects. Hum Reprod 2001; 16(5): 972-8.

[42] Anniballo R, Ubaldi F, Cobellis LE, et al. Criteria predicting the absence of spermatozoa in the Sertoli cell-only syndrome can be used to improve success rates of sperm retrieval. Hum Reprod 2000; 15(11): 2269-77. 